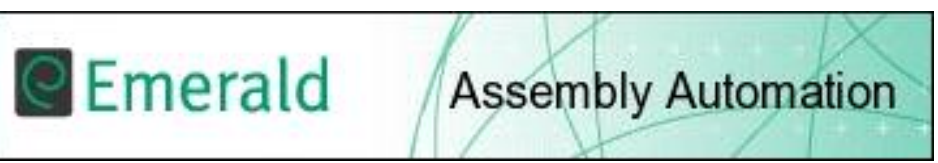

\title{
CONTROLLING THE DIRECTION OF WALKIE TYPE FORKLIFTS AND PALLET JACKS ON SLOPING GROUND
}

\begin{tabular}{|r|l|}
\hline Journal: & Assembly Automation \\
\hline Manuscript ID: & AA-08-014.R1 \\
\hline Manuscript Type: & Original Article \\
\hline Keywords: & $\begin{array}{l}\text { Sensors }<\text { Sensor Review, Teach pendant }<\text { Programming }< \\
\text { Industrial Robotics, Man/machine interface }<\text { Industrial Robotics, } \\
\text { Automated guided vehicles (AGV) }<\text { Industrial Robotics, AGVs }< \\
\text { Part presentation }<\text { Assembly, Man/Machine interfaces }<\text { Assembly }\end{array}$ \\
\hline \hline
\end{tabular}

\section{今 scholarONE" \\ Manuscript Central}




\section{CONTROLLING THE DIRECTION OF "WALKIE" TYPE FORKLIFTS AND PALLET JACKS ON SLOPING GROUND}

\section{INTRODUCTION}

This paper describes simple and affordable systems to assist hand truck users to steer their vehicles (such as walkie-type forklifts or pallet jacks) across sloping ground without veering off course. The intention in this research was to develop an electronic solution to effectively lock swivelling wheel steering positions to driver-control. Correction is applied by means of differential motor drive. The systems are tested on a specific configuration with two drive wheels and one or two rotating wheels but they can be attached to many standard powered forklifts.

Powered industrial trucks are used for moving material in the workplace. Some are fully automated, for example DaimlerChrysler's research laboratory in Berlin has developed an autonomous forklift truck for automating materials handling operations (Kochan, 2002) but despite advances in autonomy, there will always be a need for some human involvement in vehicle teleoperation (Fong, 2001).

Some high lift trucks can be used to raise loads up to 30 or 40 feet above the ground, deposit the material on a rack or mezzanine or another elevated factory location, and subsequently retrieve and lower the material. Some vehicles are used to raise a palletized load just a few inches above the floor and to move that load to another location in a warehouse or other indoor workplace. Some unpublished studies have investigated the mobility characteristics of these and similar vehicles but most of these have tended to concentrate on manual forklifts or driven powered forklifts. 
Little research has considered industrial hand truck fork lifts. Work has investigated steering systems for wheeled vehicles (Zou, 2006), user interfaces for tele-operation (Kay, 1997) and teleoperation of wheeled vehicles (Maza, 2004) . Applicable standards are ME 1910.178 "Powered Industrial Trucks" and ANSI B56.1 "Powered Industrial Trucks".

The types of vehicle considered in this research work are shown in Fig 1 and Fig 2. Generally, only electric and some specially designed LP or diesel trucks are suitable for factory use. Gasoline powered trucks are not usually used inside factories. Some general tele-operating systems that might be applied to these types of vehicles are described in Desbats et al (2006), DeJong et al (2006), Borenstein et al (1990), Shao \& Nonami (2006), Okamura (2004) and Lumelsky \& Cheung (1993). Automatic guided vehicles are described in Love et al (2007) and Rocha et al (2007). They are included here for reference and wider reading.

The research described in this paper aims to make the use of this type of equipment safer. Each year in the United States, over 100 employees are killed and 36,000 are seriously injured in accidents involving fork lift trucks and pallet carriers (Mustang, 2006). This is the second leading cause of occupational fatalities in "industrial" type workplaces. As dangerous as they are, these industrial vehicles sometimes do not get the respect due to them as they simply don't "look" all that dangerous. The truth is, however, that a forklift can weigh as much as a mid-size car. Forklifts have no "crush zones" to absorb energy in a collision, no padded dash or safety glass windshield in front of the operator to reduce injury in a collision, and by the very nature of the job that they do, they can easily tip over, especially on a slope. 


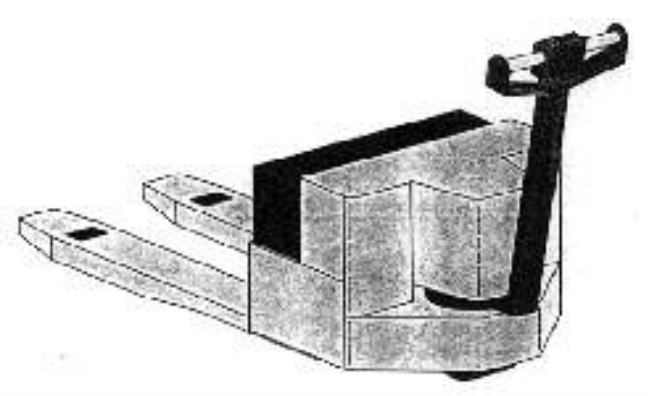

Figure 1: Typical low lift walkie-type pallet carrier

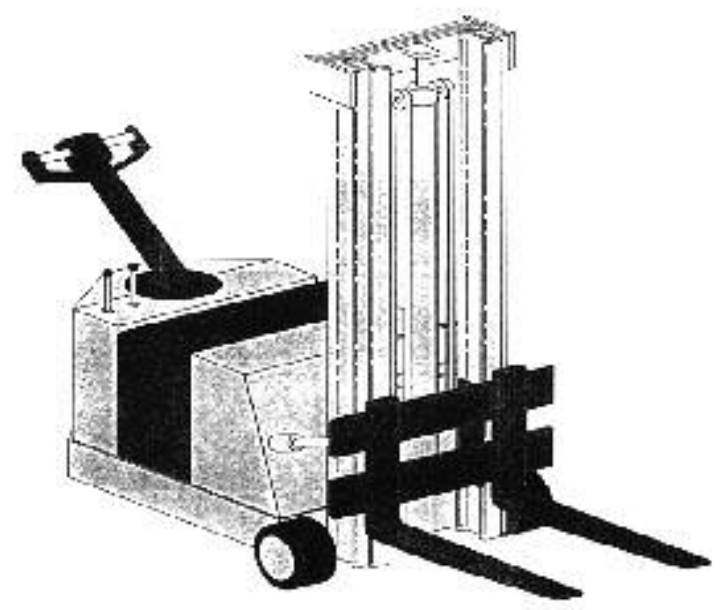

Figure 2: Typical high lift counterbalanced forklift

Hand trucks may become unstable because of high loads and their characteristic mode of steering (sometimes steering with rear wheels while being powered by front wheels, or steering with front wheels while being powered by rear wheels). Moving loads upward, downward, forward, and backward causes a shift of the center of gravity and that can adversely affect vehicle stability, especially on slopes. When a load is raised or moved away from the vehicle, the vehicle's longitudinal stability is decreased. Any of these actions on a slope during a veer can be very dangerous. 
Speed and direction of powered hand truck forklifts is usually controlled with a moveable arm or possibly a joystick, and that joystick can be remoted in dangerous environments (Broach, 2006). Joystick or arm movement in a selected direction causes a vehicle to start a turn in that direction. If a driver applied more movement then the vehicle will turn more sharply. Similarly for speed, when a variable control is progressively moved, the forklift will progressively increase speed.

These types of forklift or pallet jack generally have swivelling wheels and that simple system provides manoeuvrability. The drive wheel(s) rotates at speeds determined by a variable grip. If there is a single drive wheel then the arm has to be moved to steer the vehicle. If there are two drive wheels then to go forwards in a straight line, both drive wheels rotate at the same speed. To turn, one drive wheel rotates faster than the other.

Problems with this configuration occur when a forklift is driven along sloping ground because swivelling wheels or the arm can swivel in the direction of the slope. Gravity causes the forklift or pallet jack to start an unwanted turn or 'veer'. If a truck begins to tip on a slope then a natural reaction is to turn down the slope and that can make the whole situation worse if the truck then attempts to turn back up the slope.

A person driving usually senses this and applies correction to counter this veer. This causes extra work as the forklift or pallet jack tries to go in an unintended direction. This situation is exacerbated for on/off switch controllers, as these switches cannot provide fine control to trim and compensate for veer. A switch user will frequently need to hop between directions and forward control switches to keep control of the intended direction. 
Forklifts and pallet jacks can also veer when driven over a flat surface. This can occur as a result of imbalances in the drive motors, wheel wear and mechanical friction of moving parts and swivelling wheel / wheel bearings. Some modern forklift controls can electronically trim and compensate so that a machine can hold a straight direction on level ground, however they will not automatically correct for changes in forklift or pallet jack loading and sloping ground effects.

To address these problems, some systems were considered to model the environment around the forklift [Sanders (1995a)], predict terrain ahead of the forklift [Urwin-wright (2002), Urwin-wright (2003) and Stott (2000)], consider forces on the forklift [Sanders(2007)] or plan paths for the forklift [Goodwin (1997) and Sanders (1995b)]. These systems were tested but rejected as too complex and / or too expensive to apply to this simple problem. Other researchers had investigated the use of safety restraints to assist in forklift use in unpublished work but it was considered better to investigate ways of assisting users in steering their forklifts.

Some unpublished studies have investigated changing wheel-camber-angle to reduce veer but they have had differing results. Increased wheel-camber has some minor disadvantages, such as increased wheelbase and possibly decreased pallet jack height although some studies with wheelchairs have reported some advantages [Brubaker CE (1986)] and Trudel G (1997) suggested that camber improved manoeuvrability and stability on a side slope. Increased forklift width can improve turning stability and reduce downward turning tendency on side slopes but any advantage in that change of design may be cancelled out by problems when a user is negotiating obstacles.

To avoid subjectivity in the results, forklifts and veer systems were tested with repeatable and standard inputs and tests included standard ramps inside laboratories and set outside courses for comparison. Only after results were obtained from the standard tests were tests conducted with 
human forklift drivers. The work described in this paper concentrated on the concepts, application and results of the work rather than the physical implementation of a marketable product.

\section{THE PROBLEM}

The center of gravity of an unloaded forklift is designed to be along the centerline, half way between the rear and front axles (or in line with the single drive wheel). If the centre of gravity moves outside of the stability triangle of a truck then the truck will tip over, with potentially fatal results. Loading of the forks, raising the forks, braking and driving on a downward slope all move the center of gravity forward. Driving on a side slope, turning or the mast being struck by falling material moves the center of gravity side to side.

Use of these trucks on ramps or pavements with changes in slope can be dangerous and vehicles could stall, lose traction or run-away. When a walkie-type forklift or pallet jack tips over, the operator can usually step backwards, perpendicular to the direction of the vehicle's fall, to avoid injury (such as being crushed) but if the steering arm has been moved to a dangerous position on a side slope or the operator has moved below the hand truck in an effort to reduce veer then the danger can be more significant. The vehicle could skid, tip over, or fall off a loading dock or other elevated walking or working factory surface. This can all be made more dangerous because the load being carried might partially obscure the operator's vision.

Truck stability on a slope is affected by the load weight, load stability (shifting loads on a slope can cause serious tip-overs), speed, uneven ground, cornering, braking, brake conditions, having a soft tyre(s), surface conditions (slippery, uneven, depressions etc.) and possibly objects striking the mast. Tip-overs are the most common forklift mishaps resulting in fatal injuries (National Agricultural 
Centre, 2008). The other two in the top three are pedestrians struck by trucks and bystanders and operators struck by falling loads (sometimes on slopes). Operator error can also add to the situation due to carrying a load too high, incorrect use of tilt, disengaging the clutch, not having forks fully inserted, travelling forward down a slope while loaded (Reversing vehicles 2006), carrying hitchhikers, not being able to see clearly while moving, keeping forks too high, driving too fast across a slope or not having a load centrally placed (Workplace transport safety, 2005; Safety, 2006; Managing vehicle safety, 2005).

People can expend considerable energy, get frustrated and can end up in crash situations as a result of forklift veer. Early experiments showed that carefully setting up forklift control for straight line balance and optimizing motor compensation was not good enough to overcome veer on even gentle slopes. Most forklift drivers reported veer problems with their forklifts. Sometimes this could be corrected by reprogramming the controller, but this was always carried out on a level and flat floor surface. The general procedure required a driver to drive along a corridor in both directions to demonstrate the tendency of the veer. Adjustments would be made to the drive program that changed the power drive balance to counteract the veer.

Drivers reported problems with veering off course even when their forklift had a well balanced motor drive. This indicated that forklifts were susceptible to the subtleties of ground slopes and changes in surface texture. These variances made it difficult to anticipate every ground effect.

It was necessary to develop a reproducible (repeatable) method to assess how forklifts and control system performance were affected by sloping ground. In some cases a forklift could become undrivable due to problems with veer and doing all the testing with human operators would have been dangerous. 
Forklifts could veer when driven over a flat surface as a result of imbalances in the drive motors, tyre-wear and mechanical-friction of the moving-parts and swivelling wheel or wheel bearings. Some modern forklift controls can electronically compensate the system so the hand truck will hold a straight direction on level ground, however they cannot automatically correct for changes in forklift loading and sloping ground effects. Wheel slip could also be a problem on even mild slopes (up to $5^{\circ}$ ) and could contribute to loss of control.

All forklift drivers are affected by veer if they drive or work on a slope. Skilled and competent drivers can correct veer for themselves as a natural response but it can be a problem for switch controls that select drive direction separately as switches cannot provide the fine steering control necessary to control veer on a slope

\section{DETECTION OF FORKLIFT VEER}

Veer is normally detected by the forklift driver (using their eyes to see and possibly ears to provide a sense of balance), and then corrected by processing (using their human brain), and bio mechanical interface (muscle action), control (arm, joystick or digital switch or switches). This all results in added complexity and work for forklift drivers. In addition, driving across a slope can be dangerous and so some veer detection methods were considered:

Odometer: When commanded to go in a straight line, each drive wheel rotation is measured. If any difference is detected then control is applied to keep them the same. Jockey-wheels friction-coupled to a drive wheel can provide accurate ground speed (even when considering slight differences in wheel diameter). This was tested but found to be more complicated and less satisfactory than detecting wheel swivel. 
Optical: Ground movement sensing is similar to an optical (ball-less) mouse. This was tested but it was found that surface texture variations and reflectivity of ground surface could cause problems (particularly in wet and dry conditions). The ground detection range could have been extended by using an optical magnifier but this was not attempted.

Inertial: Gyro / rate of rotation sensor measuring the precession of a gyro to the rotation of the forklift when veer causes turning downhill. Consideration must be given to the effects of other variables, for example slopes, shock, vibration, drift and time to establish a reference heading. This was not tested and was only considered in the literature.

At the time of writing the relative complexity and cost of these systems remains high compared to using swivelling wheel-swivel-detection.

Wheel swivel detection: The selected method for detecting veer was to use measurement of wheelangle. This could provide direct measurement of steering error and feed back to the forklift drive control system.

\section{CONTROL LOGIC}

A single swivelling wheel could lose contact with the ground and therefore averaging two swivelling wheel -detector-outputs provided better feedback but to simplify the systems, experimental trials were based on a single swivelling wheel. To reduce the tendency for misreads if the swivelling wheel lost contact with the ground, the system incorporated a shortterm-memory and any sudden swivel changes were ignored by the correction system. Locking the swivelling wheels manually required substantial further development of the swivelling 
wheel mechanics and so swivelling wheel locking was effectively achieved electronically by providing feedback-information to the forklift drive controller. The intention was to develop an electronic solution to effectively lock swivelling wheel steering positions to driver-control." The wheels are straightened by means of differential motor drive. Although that might sometimes fight with the driver's steering intentions, it improved performance on dangerous sloping ground.

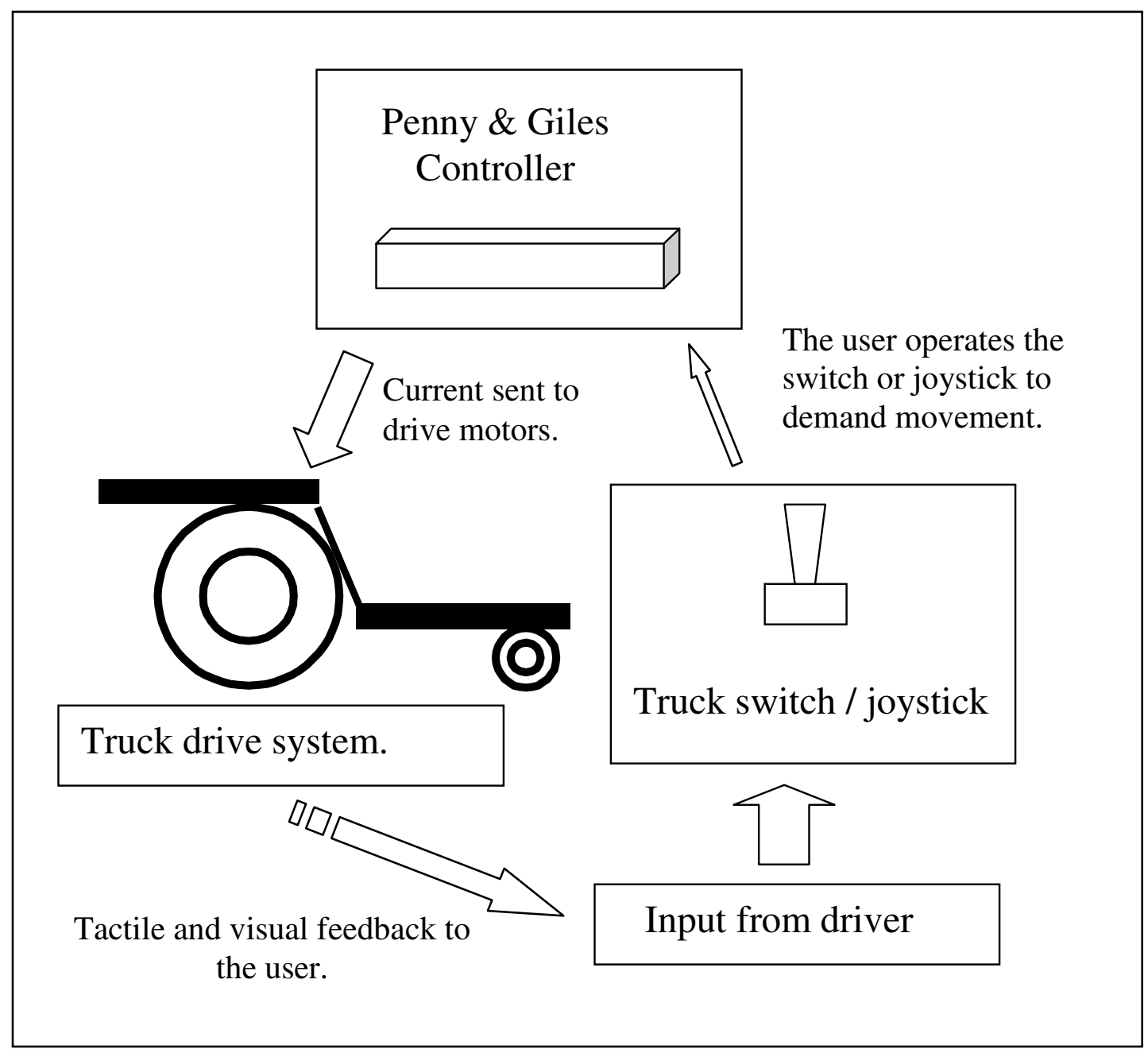

Figure 3 - The unmodified forklift truck

The forklift truck base consisted of a front wheel drive chassis fitted with a Penny \& Giles PG8 controller. The base consisted of a heavy steel plate chassis to provide stability and rigidity. The truck had four wheels with two driven wheels and two caster wheels. The casters were 
fitted to support the loading on the base. Driving wheels were powered by two parvalux motors through a worm drive right angle reduction gearbox. Altering the differential of rotational speed of the driving wheels effected steering. If the wheels were set to rotate in opposite directions then truck base could spin. A parking brake was automatically applied to the motor output shafts when the forklift was stationary. The brakes were automatically released when the joystick or switch inputs were operated.

The controller could be connected to any input device with a suitable interface. The controller microprocessor could be programmed via a socket on the controller housing. The dynamic response to command inputs could be programmed by using programmer DP1b available from Penny \& Giles Drives Technology Ltd. The function of the programmers was to assign the initial controller parameters which set the normal drive characteristics of the forklift truck. The control system for the basic forklift was open loop if only the hardware was considered but a feedback route existed through the driver. The new systems were created to provide another route for the feedback path to augment a user who could not easily feed the correct information back into the system when the truck was on a slope.

In order to correct the trajectory of the fork lift truck, it was necessary to make changes to the motor control voltages. A number of systems for changing the motor control voltages were considered. These included using an SPI compatible digital to analogue converter (DAC) or the pulse width modulation (PWM) outputs of the micro-controller. An interface was created for connection to the dual PWM outputs in favour of using an SPI compatible DAC. The PWM outputs of an ATMEL 8515 micro-controller were a convenient way to produce a DC voltage of magnitude $0-5 \mathrm{~V}$. As the output from the micro-controller was PWM it was not a smooth DC voltage and needed to be conditioned before it was of sufficient quality to be mixed 
with the original joystick or switch voltages. As a PWM voltage is a pulse of varying duration, repeated at a fixed time interval, the controller would not accept an un-smoothed PWM voltage as a "safe" input voltage and would "trip", assuming a fault condition. The raw PWM voltage needed to be approximated to a joystick or switch quality DC voltage so a simple smoothing circuit was created and fed to a level shifting circuit. This made the PWM voltage acceptable to the inputs of the controller. The level shifting circuit was added to make best use of the PWM range. A certain PWM value could be set as the "null" value. At this value (0V) the PWMs did not change the input to the controller. The PWM value could be change to increase the controller voltage or to decrease it. The motors were now controllable and the switch or joystick inputs could be over-ridden or negated by altering register settings in the micro-controller.

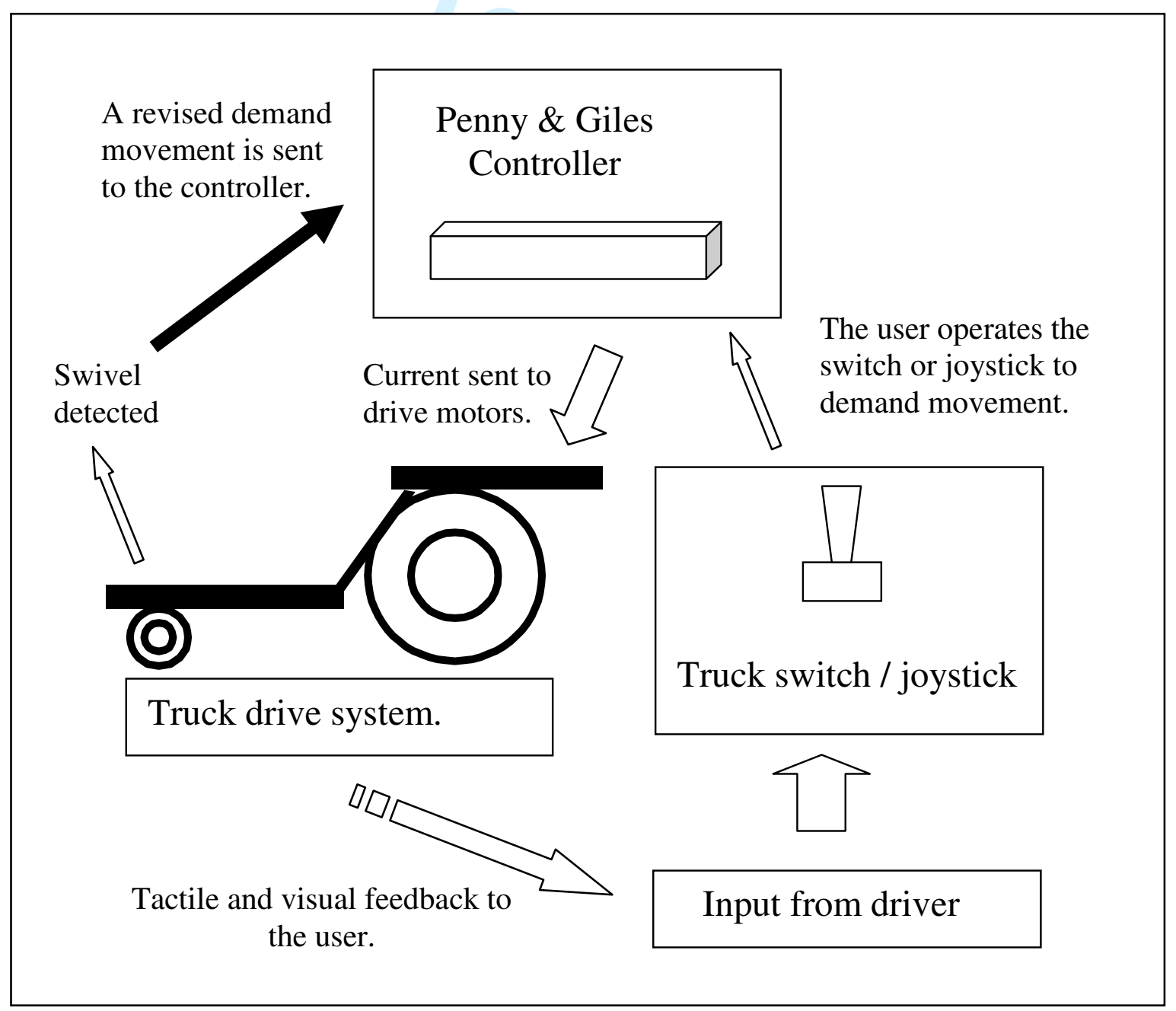




\section{Figure 4 - The modified forklift truck}

\section{PROTOTYPE TESTING}

At the point when veer was first detected, the hand truck had already begun to alter course. The job of the correction system was to minimize this drift from the required course. The amount of compensation feedback determined how accurately the forklift held its course against gravity pulling against the forklift. The amount of applied feedback was critical to avoiding problems of instability.

In order to study the effects of forklift loading in a controlled environment, a rolling-road was created in the laboratory to use as an assessment tool. For a truck with two drive wheels, both drive wheels needed to rotate at the same speed for a hand truck to travel in a straight line (assuming they were equal in diameter). An accurate assessment was obtained by using tacho-measurement wheels coupled to the forklift wheels. Tacho sensing of the motor drive shaft speed did not take into account variances of wheel diameters and wheel slip. Remote tacho-sensing provided sufficient accuracy for the straight line test but was not accurate enough to overcome drive loading. The rolling-road test-bed (shown in Fig 5) was created to assess drive motor and control performance. This test-bed incorporated tacho-rotation speed-sensing and variable-dynamic-loading. The test-bed provided individual distance counters for left and right drive-wheels, a differential drive balance indicator (veer) and drive speed Kph indicators. It was necessary to provide separate speed and distance information to determine each of the motor/drive speed characteristics separately. 


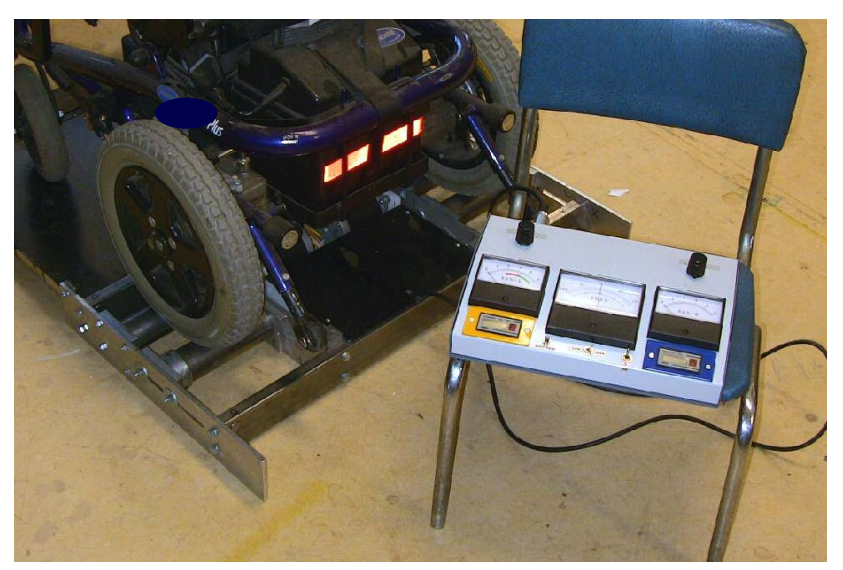

Figure 5 - rolling road test bed

Some commercial forklift controllers had inbuilt programmable drive speed compensation. This could reduce speed variation due to load changes, for example driving up or down slopes or over bumps and curbs. Compensation feedback was derived from the drive motor Electro Motive Force. This related to a generated motor voltage that changed in proportion to speed. This method was effective for sudden changes in motor speed, for example low edges or surface irregularities. Problems occurred even with these systems with gradual changes over longer distance where veer became significant. If motor compensation was increased to reduce veer then the systems became unstable.

Trials with the test bed were conducted on simple forklifts to evaluate the effectiveness of the rolling road system. These trials demonstrated the importance of measurable parameters that affected veer that were not apparent during tests with forklift drivers on flat surfaces.

Some modern forklift control systems incorporated programmable load compensation. This helped to keep forklift speed constant. For example, if increased load was applied to the drive motor, the control system applied more power to keep the speed constant. Motor compensation was applied in 
equal amounts to both motors. When testing load compensation with the rolling test bed, then veer characteristics were affected by changes in load. This indicated that in practice powered forklifts may not veer on level ground, but the effect of motor compensation could introduce a veer when driving up or down a small gradient.

If there were two drive wheels then the acceleration or deceleration characteristics of each drive motor were not always matched. The distance (pulse count) for each drive wheel was measured from rest to the set drive-speed and then to rest. There could be a miss-match in the count value of each drive-wheel and this error could skew the heading of a forklift when starting or stopping, even when drive wheel speeds were balanced and the forklift was on level ground.

Trials with the rolling road demonstrated that many variables affected veer. Optimizing parameters on a flat surface was only valid for that sort of environment. A problem with conventional forklift control systems was the way in which forklifts responded to control actions. To implement a solution it was necessary to provide global feedback within the control system.

To provide meaningful feedback, consideration was given to the factors that could degrade accuracy. For example, when considering odometer methods, there could be issues with changes in wheel diameter and wheel slip. Swivelling wheels provide steering manoeuvrability, however they also cause a susceptibility to veer. With Car steering, the turning angle is locked to driver control via the steering wheel. If forklift swivelling wheels were locked straight ahead then veer becomes less of an issue but manoeuvrability can be lost.

The intention in this research was to develop an electronic solution to effectively lock swivelling wheel steering positions to driver-control. Measurement of swivelling wheel-swivel provided an 
error signal that was fed back to a control system. To test the methods, a small swivel-detector was created that could be attached to a swivelling wheel bearing on a test vehicle (shown in Fig 6). This provided representations of left, right and centre swivel-direction outputs.

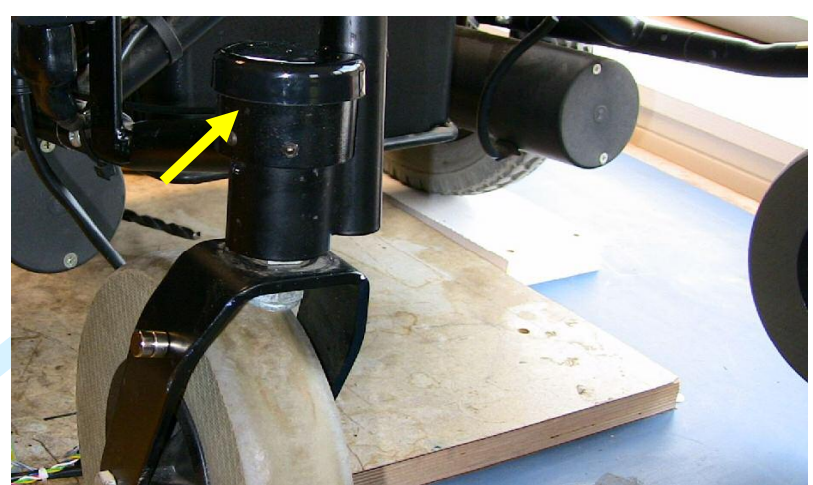

Figure 6: Swivel-detector (marked by the arrow)

Correction feed back was applied when a wheel swivelled from the centre position. The amount of compensation feedback determined how accurately the forklift held its course against gravity. The experimental tests indicated that the amount of veer was not always related to the slope camber but could change with gradient depending on the control system and motor compensation imbalance. Furthermore, ground surface effects could also induce some veer even on relatively level ground.

\section{TESTING OF THE NEW SYSTEMS}

The new veer correction systems were tested in the laboratory and on sloping ground. Tests were conducted first using switch controls as these were considered to be more difficult to use in correcting veer (although the methods were then easily transferred to variable controls).

The number of steering corrections needed to complete a series of test runs was counted. During uncorrected runs, there was a dominant veer downhill caused by the path camber. 
In a typical set of test runs along a path with a slope of 3 degrees, an average of eight left-switch corrections were needed by a forklift driver to maintain the direction of a hand truck. When tests were repeated with the veer-control-system engaged then the number of corrections was notably reduced, requiring an average of only a single right correction and a single left correction to complete each test run. The forklift was weighted with $30 \mathrm{Kg}$. The difference between the trajectory with the system engaged and without the system was significant.

The series of diagrams in Figs 7, 8, 9 and 10 show what the correction system did during a test run. Initially the forklift moved in a straight direction (Fig 7). Once a veer had been detected by a change in swivelling wheel angle (Fig 8) then the system acted to restore the forklift to the original course (Fig 9). The distance taken to correct the veer depended on the amount of feedback applied back to the controller (Fig 10).

Twenty tests were undertaken at the University of Portsmouth. A typical set of test results is shown in Table One and Table Two. Table One shows a set of results from an outside test on a path of length 28 Meters and an average camber / slope of $3^{\circ}$ without the new veer system and sensors engaged. Table Two shows the improved results from the same slope with the sensors and systems engaged. 


\section{What the correction system did on the test run}

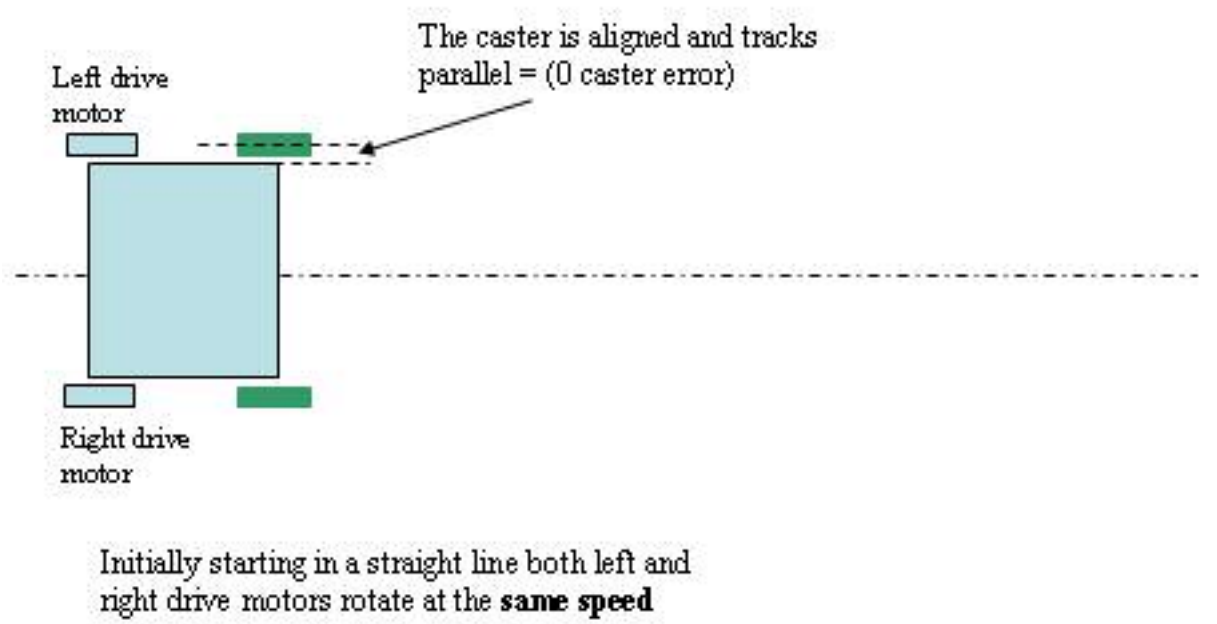

Figure 7: hand truck driving in a straight line

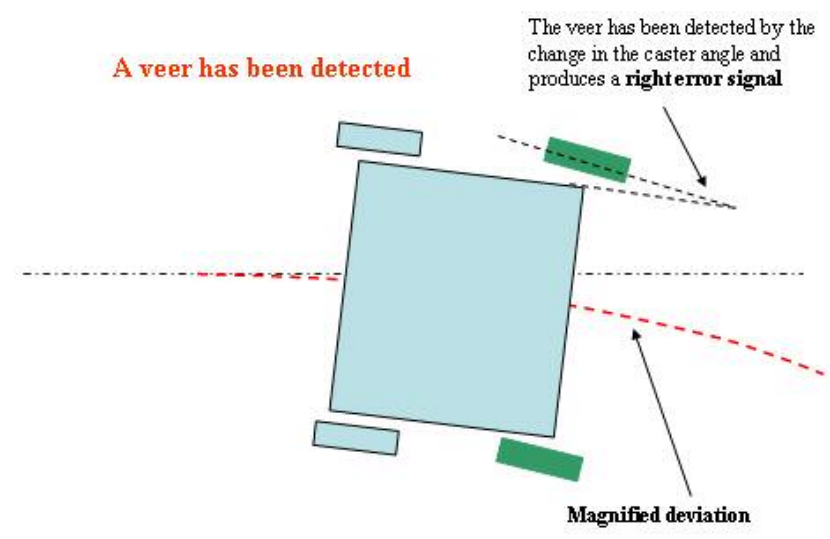

Figure 8: Veer detected 


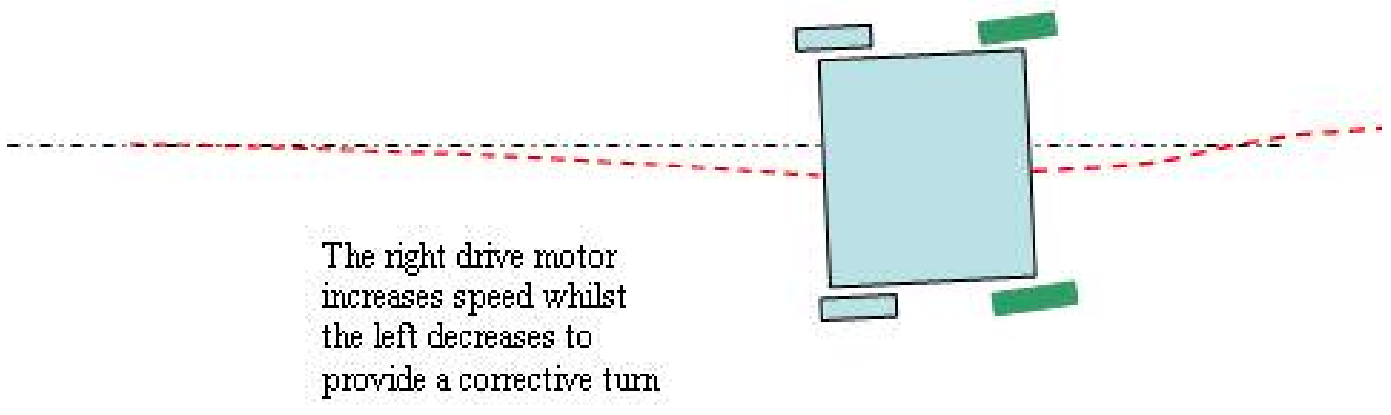

Figure 9: Restoration of the course

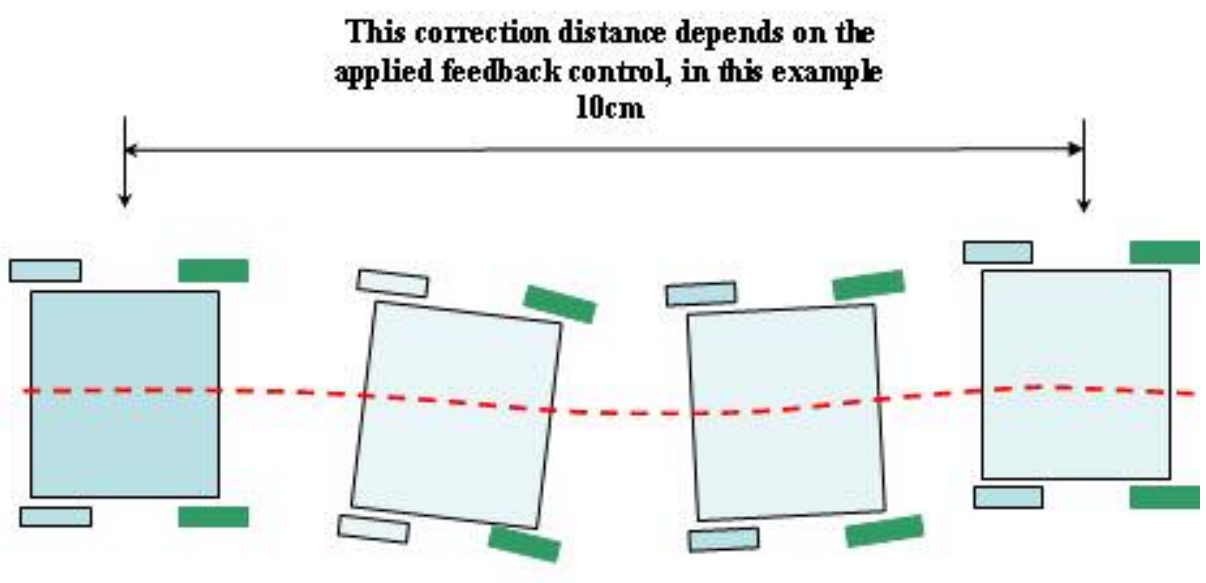

Figure 10: Correction distance 


\section{Run test with no applied veer correction test.}

Time to complete run $=1 \mathrm{~min}: 7 \mathrm{secs}$

Total number steering corrections required $=8 \mathrm{left}$

Correction distance derived from time / distance approximations

All Left corrections after start of run distance in meters (M)

$$
\begin{aligned}
& 1^{\text {st }}=3.7 \\
& 2^{\text {nd }}=6.4 \\
& 3^{\text {rd }}=12.3 \\
& 4^{\text {th }}=15.6 \\
& 5^{\text {th }}=18.5 \\
& 6^{\text {th }}=22 \\
& 7^{\text {th }}=25 \\
& 8^{\text {th }}=27.4
\end{aligned}
$$

TABLE ONE

\section{Test with veer correction applied.}

Time to complete run 49 secs

Total number of steering corrections required $=1$ right and 1 left total

Approximate correction distance in meters (M)

$$
\begin{aligned}
& 1^{\text {st }} \text { Right correction distance }=9.4 \\
& 1^{\text {st }} \text { Left correction distance }=22.4
\end{aligned}
$$

TABLE TWO 
It was also noted during testing with forklift drivers that when forward drive was selected after a turn manoeuvre then empty (unloaded) forklifts could be 'snapped' back into straight-forward drive too quickly. This was because of the resulting swivelling wheel angle after the turn which was 'offcentre'. When forward drive was selected then the fast acting correction system tried to restore the forklift to a straight-line direction too quickly. This harsh correction was not desirable for drivers who were used to softer control characteristics. To reduce this effect a short 'post-turn veercorrection-delay' was introduced after a turn manoeuvre. This provided time for the forklift to softly restore the straight line direction before veer correction cut-in and the resultant system worked well.

The limit of veer correction was dependant on the traction capabilities of each forklift, the power of the motors coupled with the wheel grip characteristics and the weight distribution over the ground surface (which could be rough or smooth). The systems tried to correct for veer even if drive wheels skidded. This could be a problem if feedback was too aggressive, as a sharp response could cause skid (loss of traction).

\section{CONCLUSION}

Some simple systems have been described that assist hand truck operators in steering their forklifts across sloping ground without veering off course. The new systems are simple and affordable and could be attached to many standard powered forklifts. The systems overcame the problems associated with forklifts that steer using two swivelling wheels and meant that less work was required from hand truck operators as their fork lifts tended to travel in the desired direction. The systems were especially useful for trucks driven with switches as switches could not provide fine control to trim and compensate. 
Several veer detection methods were considered but swivelling wheel angle measurement was selected as the cheapest and simplest option to provide feedback. Effectively, an electronic solution was created to match swivelling wheel steering position to driver control. The new systems were successful, robust and not affected by changeable parameters. Test runs with and without the new veer correction system demonstrated that the simple feedback system could reduce the amount of effort needed by a driver to counteract any tendency for a forklift to veer off course on a slope.

The next phase of the work is to equip some new powered forklifts with the veer control system for longer-term trials and evaluation of the veer control in frequent operation. Commercial development has not yet been explored but the device may be marketable because of its ease of use and transferability from one forklift to another.

The veer control systems could also assist tele-operated forklift truck operators; reducing what can be a struggle to keep some forklifts on their correct course on slopes. There could also be applications in self-propelled mobility systems. In future work a combination of veer correction and boundary detection will be used on forklifts. Very early results suggest that a combination of boundary sensing and anti-veer systems may provide a further and demonstrable reduction in the amount of effort required by the operator but that work is ongoing. Although the mode of steering specifically considered in this paper was steering with rear wheels while being powered by front wheels, the system is also suitable for front wheel steering while being powered by rear wheels. 


\section{References}

Borenstein J (1990). Tele-autonomous Guidance for Mobile Robots. IEEE Transactions on Systems, Man, and Cybernetics, Special Issue on Unmanned Systems and Vehicles Vol. 20, No. 6, Nov/Dec 1990, pp. 1437-1443.

Brubaker CE, McLaurin CA, McClay IS. (1986). Effects of side slope on wheelchair performance. J Rehabil Res Dev. 23 (2), pp 55-58.

Desbats P, Geffard F, Piolain G and Coudray A (2006). Force-feedback teleoperation of an industrial robot in a nuclear spent fuel reprocessing plant. Industrial Robot: An Int Jnl, Vol 33, No 3, pp 178 - 186 ISSN: 0143-991X.

DeJong BP, Faulring EL, Colgate JE, Peshkin MA, Kang H, Park YS and Ewing TF (2006). Lessons learned from a novel teleoperation testbed. Industrial Robot: An Int Jnl, Vol 33, No 3, pp 187 - 193. ISSN: 0143-991X.

Fong, T; Thorpe, C (2001). Vehicle tele-operation interfaces. Autonomous Robots. Vol 11, No 1, pp 9-18.

Goodwin MJ, Sanders DA, Poland GA, et al (1997). Navigational assistance for wheelchair-users. Jnl Systems Architecture 43 (1-5), pp 73-79.

Kay, JS; Thorpe, CE (1997). An examination of the STRIPE vehicle teleoperation system. IROS '97 - Proc' 1997 IEEE / RSJ Int' Conf' on Intelligent Robots and Systems: Innovative robotics for real-world applications, Vols 1-3, pp 1152-1157.

Kochan A (2002). Robotic production assistants for working alongside the human operator. Assembly Automation, Volume 22, Number 1, pp. 26-28.

Love P K and Gu J (2007). An autonomous self contained wall climbing robot for non-destructive inspection of above-ground storage tanks. Industrial Robot: An Int' Jnl, Vol 34, No 2, pp 122 - 127. ISSN: 0143-991X.

Lumelsky VJ and Cheung E (1993). Real-time collision avoidance in teleoperated whole-sensitive robotarm manipulators. Systems, Man \& Cybernetics, IEEE Transactions. Vol 23, No 1, pp 194203. ISSN: 0018-9472

Managing vehicle safety at the workplace (2005). Various authors. A short guide for employers. INDG199 ISBN 071760982 0. Available from HSE Books.

Maza, M; Baselga, S; Ortiz, J (2004). Vehicle teleoperation with a multisensory driving interface. Proc' 7th International Conference on Climbing and Walking Robots (CLAWAR 2004), from Climbing \& Walking Robots (2005), pp 437-445.

McFee, J (2006). The Canadian Forces ILDS - A militarily fielded, multi-sensor, vehicle-mounted, teleoperated landmine detection system - art. no. 62172G. Proceedings of SPIE, the international society for optical engineering. Vol 6217. Page G2172. ISSN: 0277-786X

Mustang (2006). Safety Minute Wk 37, September 142006. 
National Agricultural Centre (2006). Cert' of competence in forklift truck operations, available form Stoneleigh Park, Warwickshire CV8 2LG.

Okamura AM (2004). Methods for haptic feedback in teleoperated robot-assisted surgery Industrial Robot: An International Journal. Vol 31, No 6. pp 499-508.

Reversing vehicles (2006). Various authors. INDG148. ISBN 071761063 2. Available from HSE Books.

Rocha R, Cunha A, Varandas J and Dias J (2007). Towards a new mobility concept for cities: architecture and programming of semi-autonomous electric vehicles. Industrial Robot: An Int' Jnl. Vol 34, No 2, pp 142 - 149. ISSN: 0143-991X

Safety in working with lift trucks (2006). Various authors. HSG6 ISBN 071761781 5. Available form HSE Books.

Sanders DA (1995a). Real time geometric modeling using models in an actuator space and cartesian space. Jnl of Robotic Systems 12 (1): 19-28.

Sanders DA (1995b). The modification of pre-planned manipulator paths to improve the gross motions associated with the pick and place task. ROBOTICA 13: 77-85 Part 1.

Sanders DA (2007). Viewpoint - Force sensing. Industrial Robot - an international journal. 34 (4): 268-268.

Shao H and Nonami K (2006). Bilateral control of tele-hand system with neuro-fuzzy scheme. Industrial Robot: An Int' Jnl. Vol 33, No 3, pp 216 - 227. ISSN: 0143-991X.

Stott IJ and Sanders DA (2000). New powered wheelchair systems for the rehabilitation of some severely disabled users. International journal of rehabilitation research. 23 (3): 149-153.

Trudel G, Kirby RL, Ackroyd-Stolarz SA, Kirkland S (1997). Effects of rear-wheel camber on wheelchair stability. Arch Phys Med Rehab 78 (1), pp78-81.

Urwin Wright S, Sanders DA and Chen S, (2002) Terrain prediction for an eight-legged robot. Journal of Robotic Systems, Vol 19, No 2, pp 91-98, published by Wiley.

Urwin-Wright S, Sanders D and Chen S (2003). Predicting terrain contours using a feed-forward neural network . Engineering applications of artificial intelligence 16 (5-6): 465-472.

Wolf E, Cooper RA, Pearlman J, Fitzgerald SG and Kelleher A (2007). Longitudinal assessment of vibrations during manual and power wheelchair driving over selected sidewalk surfaces. Journal of Rehabilitation Research \& Development, Volume 44, Number 4, Pages 573 - 580.

Workplace transport safety(2005). Guidance for employers. HSG136 ISBN 0717609359. Available form HSE Books.

Zou, G (2006). Simulation and design of the steering control system of wheeled teleoperated vehicle. Proc' Int' Conf' on Mechanical Transmissions, Volumes 1 and 2. Page 58 